\title{
COVID-19 ON BEHÇET’S DISEASE PATIENT: SHED LIGHT ON SHADOWS (CASE REPORT)
}

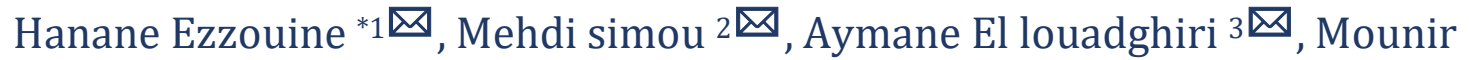

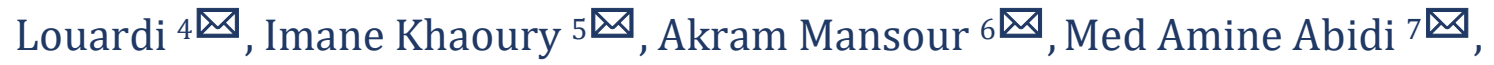 \\ Boubaker Charra $8 \square$ \\ *1, 8 Professor, Department of Anesthesiology and Intensive Care, Ibn Rochd University Hospital of \\ Casablanca, Hassan II University, Morocco \\ 2, 3, 4, 5, 6, 7 Resident, Department of Anesthesiology and Intensive Care, Ibn Rochd University \\ Hospital of Casablanca, Hassan II University, Morocco
}

DOI: https://doi.org/10.29121/granthaalayah.v8.i11.2020.1539

Article Type: Research Article

Article Citation: Hanane Ezzouine, Mehdi simou, Aymane El louadghiri, Mounir Louardi, Imane Khaoury, Akram Mansour, Med Amine Abidi, and Boubaker Charra. (2020). COVID-19 ON BEHÇET'S DISEASE PATIENT: SHED LIGHT ON

SHADOWS (CASE REPORT). International Journal of Research GRANTHAALAYAH, 8(11), 49-52. https://doi.org/10.29121/granthaa layah.v8.i11.2020.1539

Received Date: 14 September 2020 Accepted Date: 24 November 2020

\section{Keywords:}

Covid-19

Patient

Shed Light

\section{ABSTRACT}

A new family type of coronavirus (SARS-CoV-2) was first seen in Wuhan, China name coronavirus disease 2019 (COVID-19). COVID-19 primarily attacks the respiratory system, but several studies have shown that infection with SARS-COV-2 can cause thrombosis and have therefore considered COVID-19 to be a prothrombotic disease.

Behçet's disease (MB) is a systemic vasculitis. Its ethiopathogeny is still poorly understood. Blood vessels of any caliber can be affected. Arterial involvement, such as thrombosis and / or aneurysm, is possible.

This article reports the case of SARS-COV-2 infection in a patient with behcet's disease.

\section{INTRODUCTION}

A new family type of coronavirus (SARS-CoV-2) was first seen in Wuhan, China name coronavirus disease 2019 (COVID-19). It spread very quickly around the world and was accepted as a pandemic on March 11, 2020. Although COVID-19 primarily attacks the respiratory system, but Several histopathology reports and clinical case series have shown thrombosis associated with SARS-COV-2 infection and thus COVID-19 is considered to be a prothrombotic disease [1].

Behçe t's disease (MB) is a systemic vasculitis. Its ethiopathogeny is still poorly understood. Blood vessels of any caliber can be affected. This vasculitis can affect the venous and arterial territories. Arterial involvement, such as thrombosis and / or aneurysm, is possible. Lower extremity veins are frequently affected followed by iliac veins

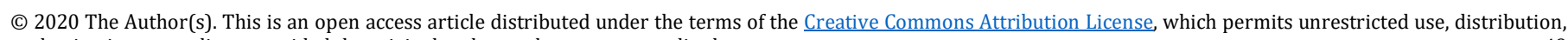
and reproduction in any medium, provided the original author and source are credited. 
and vena cava. The treatment for behcet's disease is based on immunomodulatory and immunosuppressant drugs, colchicine is one of the most preferred treatment agents of Behçet's disease [2].

Herein, we report the case of covid-19 pneumonia in a patient with behcet's disease and treated with colchicine.

\section{CASE REPORT}

76-year-old patient, type 2 diabetic under insulin therapy, hypertensive, suffering from behcet's disease for 20 years under colchicine. The history of the disease dates back to a week with the onset of dry cough, fever and flu-like syndrome. The patient was admitted for the first time to the emergency room where a thoracic scan was performed, which revealed a frosted glass appearance in favor of a viral attack (figure 1) as well as the rt-PCR for SARS-COV-2 which came back positive. In front of the worsening from the symptomatology, the patient was transferred to intensive care unit.

On admission, the patient was conscious, his blood pressure was $144 / 75 \mathrm{mmHg}$ and his heart rate was 77 beats / min, his respiratory rate was 30 cycles / min. He was suffering from hypoxemia, his pulse oximetry was $85 \%$ in the ambient air which increased to $95 \%$ with a high concentration of oxygen. He had dyspnea with a respiratory rate of 38 cycles per minute. His body temperature was $37.5^{\circ} \mathrm{C}$.

The electrocardiogram showed a regular sinus rhythm at $74 \mathrm{bpm}$, a fixed PR space of 0.16 seconds, a fine QRS, a QT measured at $400 \mathrm{~ms}$ and a QT corrected at $447 \mathrm{~ms}$ with no repolarization disturbances.

The biological findings were as follows: CRP at $62.4 \mathrm{mg} / \mathrm{L}$, hemoglobin at $13 \mathrm{~g} / \mathrm{dl}$, leukocytes at $10330 / \mu \mathrm{L}$, polymorphonuclear neutrophils at $940 / \mu \mathrm{L}$, lymphocytes at $150 / \mu \mathrm{L}$ and platelets at $181000 / \mu \mathrm{L}$. Urea at 3.3 $\mathrm{mmol} / \mathrm{l}$, creatininemia at $52 \mu \mathrm{mol} / \mathrm{l}$, AST at $22 \mathrm{UI} / \mathrm{L}, \mathrm{ALT}$ at $39 \mathrm{UI} / \mathrm{L}$, natremia at $134 \mathrm{mmol} / \mathrm{l}$, kaliemia at $4.5 \mathrm{mmol}$ / l, fibrinogen at $5.95 \mathrm{~g} / \mathrm{L}$, activated patrial thromboplastin time at 23 seconds, the the prothrombin ratio at $92 \%$, troponin at $3 \mu \mathrm{g} / \mathrm{L}, \mathrm{D}$-dimers at $1250 \mu \mathrm{g} / \mathrm{l}$.

Arterial gas monitoring shows first time at ambiant air, $\mathrm{pH}$ at 7.34, $\mathrm{PaCO} 2$ at $52 \mathrm{mmHg}, \mathrm{PaO} 2 \mathrm{at} 61.1 \mathrm{mmHg}$, $\mathrm{HCO} 3$ at $25.5 \mathrm{mEq} / \mathrm{L}$ with a $\mathrm{PaO} 2$ / FiO2 ratio at 119.8 .

Transthoracic echocardiography noted a left ventricular of normal size and function with an estimated ejection fraction of $60 \%$, no valve disease, an undilated right ventricle, and no pericardial effusion.

An ophthalmic examination with an eye fundus was performed as part of the pre-therapeutic assessment and did not reveal any abnormalities

The therapeutic management included oxygen therapy, the combination of hydroxychloroquine $200 \mathrm{mg}$ three times a day added to azithromycin $500 \mathrm{mg}$ the first day then $250 \mathrm{mg}$ per day and methylprednisolone at $80 \mathrm{mg}$ per day for 7 days, vitamin C 1 gram per day and zinc $90 \mathrm{mg}$ per day, low molecular weight heparin $0.8 \mathrm{UI}$ twice a day and suspension of treatment with colchicine.

Doppler ultrasound of the lower limb was performed, showing no evidence of deep vein thrombosis. a computed tomography angiogram was performed does not reveal any abnormalities.

7 days later, oxygen requirements decreased with progressive resolution of respiratory symptoms. On day 11 the patient left the intensive care unit.

\section{DISCUSSION}

Behçet's syndrome (BS) is a complex disorder of unknown etiology, characterized by recurrent skin mucosa lesions and uveitis. The usual onset is in the third decade. There is relapsing remitting course while the severity abates as the years pass [3]. Vascular involvement affecting both venous and arterial system is almost always associated with intensive thrombosis of inflammatory nature and can occur in up to $40 \%$ of cases [4]. Lower extremity veins are frequently affected followed by iliac veins and vena cava. Central nervous system (CNS) and joints may also be involved. Immunosuppressive agents along with colchicine are the mainstay of treatment [5]. Very few controlled and randomized studies have tackled its treatment. Therapy, therefore, depends on clinical manifestations and should be personalized.

The association "Behçet's disease - Covid19" and its therapeutic care has rarely been cited.

Hydroxychloroquine is an antimalarial molecule with anti-inflammatory action, and has been used in treating many auto immune diseases such as Behçet's disease in the eighties [6]. However, its retinal toxicity has been proven 
in numerous studies, making its prescription harder for Behcet's patients [7]. The hydroxychloroquine is also recommended for treating COVID-19 in Behcet patients after excluding an ocular lesion [8], [9].

Colchicine is one of the most preferred treatment agents for Behçet's disease, and some authors suggest that colchicine has a beneficial effect in patients with COVID-19 [10], but given the lack of absolute information on the positive effects of colchicine on patients with COVID-19 and for fear of the potential molecular interactions between colchicine and hydroxychloroquine which could lead to neuromuscular toxicity [11]. we recommended discontinuing colchicine treatment in our patient and using the combination hydroxychloroquine and azithromycin.

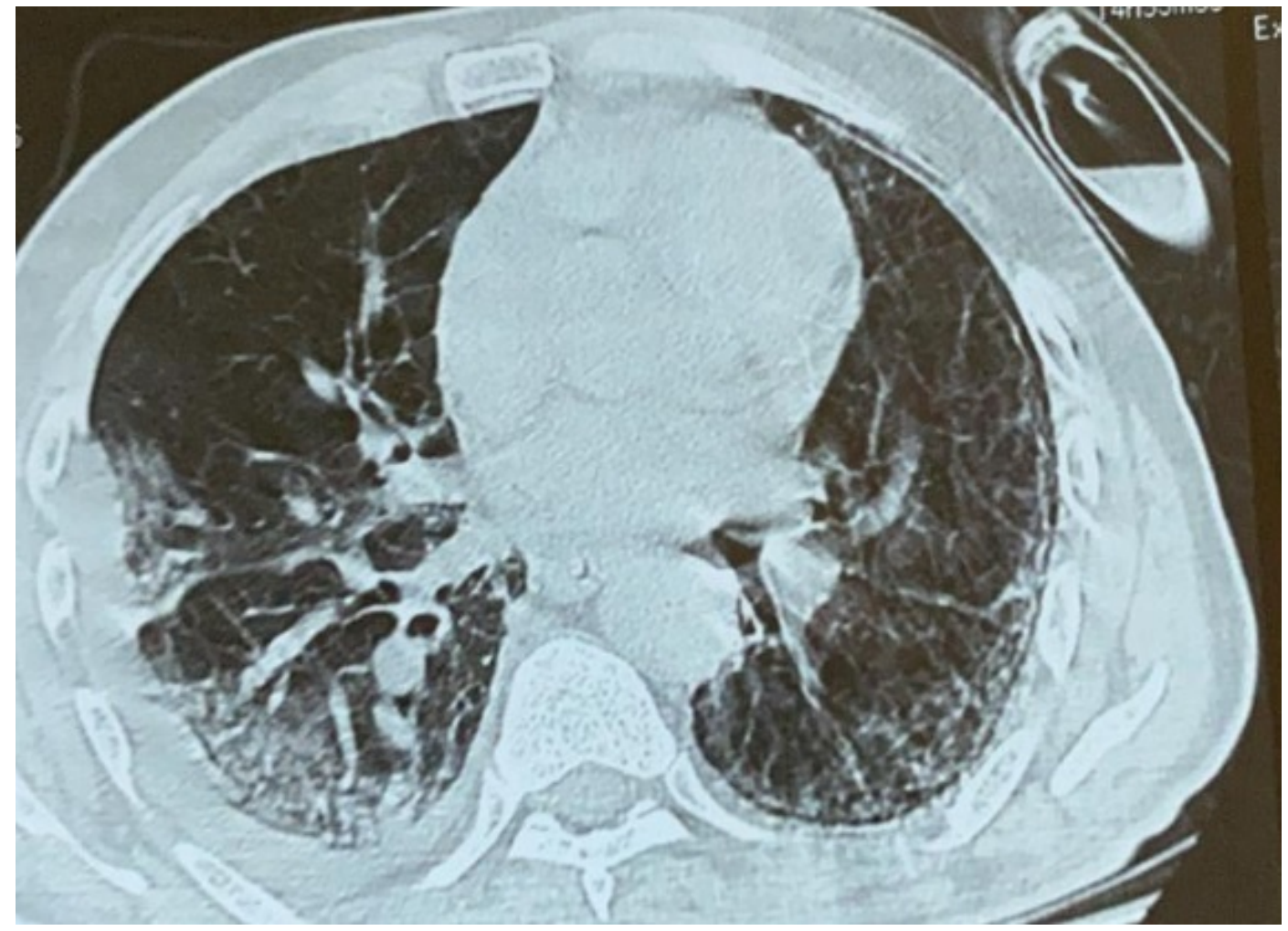

Figure 1 : Axial section of the computed tomography scan with lung parenchyma window showing a frosted glass appearance.

\section{SOURCES OF FUNDING}

This research received no specific grant from any funding agency in the public, commercial, or not-for-profit sectors.

\section{CONFLICT OF INTEREST}

The author have declared that no competing interests exist.

\section{ACKNOWLEDGMENT}

None.

\section{AUTHORS' CONTRIBUTION}

All the authors contributed equally in drafting of the manuscript. All the authors read and agreed to the final manuscript. 


\section{REFERENCES}

[1] Klok FA, Kruip MJHA, van der Meer NJM et al (2020) Confirmation of the high cumulative incidence of thrombotic complications in critically ill ICU patients with COVID-19: an updated analysis. Thromb Res.

[2] https://doi.org/10.1016/j.throm res.2020.04.041

[3] Alpsoy E, Donmez L, Onder M, Gunasti S, Usta A, Karincaoglu Y, et al. Clinical features and natural course of Behçet's disease in 661 cases: a multicentre study. British Journal of Dermatology 2007;157(5):901-906.

[4] Yazici H, Seyahi E, Hatemi G, Yazici Y (2018) Behçet syndrome: a contemporary view. Nat Rev Rheumatol 14(2):107-119. https ://doi.org/10.1038/nrrhe um.2017.208 (published correction appears in Nat Rev Rheumatol. 2018 Jan 24;14 (2):119)

[5] Seyahi E (2019) Phenotypes in Behçet's syndrome. Intern Emerg Med 14(5):677-689. https ://doi.org/10.1007/s1173 9-019-02046-y

[6] Esatoglu SN, Hatemi G (2019) Update on the treatment of Behçet's syndrome. Intern Emerg Med 14(5):661675. https :// doi.org/10.1007/s1173 9-019-02035

[7] Ben-Zvi I, Kivity S, Langevitz P, Shoenfeld Y. Hydroxychloroquine: from malaria to autoimmunity. Clin Rev Allergy Immunol. 2012; 42(2): 145- 153.

[8] Hatemi G, Christensen R, Bang D, et al. 2018 update of the EULAR recommendations for the management of Behçet's syndrome. Ann Rheum Dis. 2018; 77(6): 808- 8187Hatemi G, Christensen R, Bang D, et al. 2018 update of the EULAR recommendations for the management of Behçet's syndrome. Ann Rheum Dis. 2018; 77(6): 808- 818

[9] Gautret P, Lagier JC, Parola P, et al. Hydroxychloroquine and azithromycin as a treatment of COVID-19: results of an open-label non-randomized clinical trial. Int J Antimicrob Agents. 2020; 56:105949.

[10] Dursun, Recep, et al. "Management of Patients with Behçet's Disease During the COVID-19 Pandemic." Dermatologic therapy (2020): e14063.

[11] Parra-Medina R, Sarmiento-Monroy JC, Rojas-Villarraga A, Garavito E, Montealegre-Gómez G, Gómez-López A. Colchicine as a possible therapeutic option in COVID-19 infection. Clinical Rheumatology 2020:1-2.

[12] Lonesky, Timothy A., et al. "Hydroxychloroquine and colchicine induced myopathy." The Journal of rheumatology 36.11 (2009): 2617-2618. 